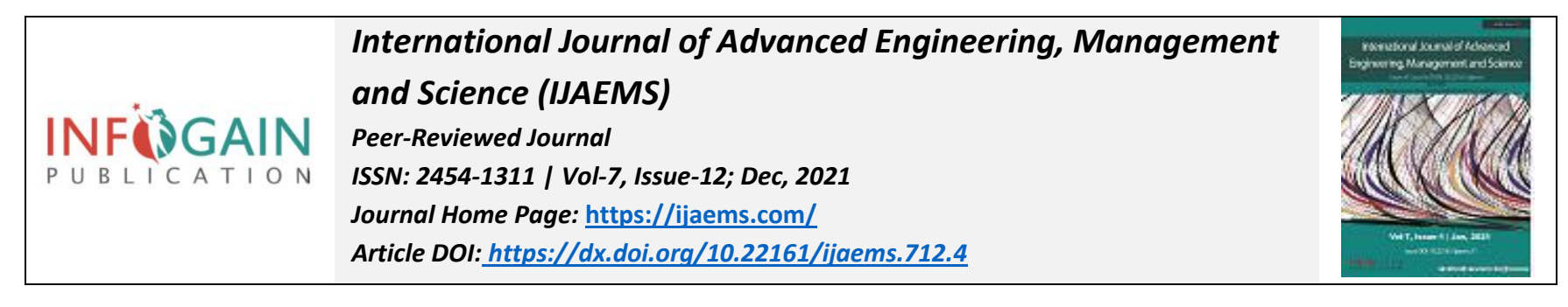

\title{
The Influence of Emotional Intelligence on Creativity, The Mediating Role of Employee Attitudes: Analysis of Mellat Holding in Kurdistan
}

\author{
Adala Sewdi Sdiq
}

Erbil, Kurdistan

Received: 14 Nov 2021; Received in revised form: 11 Dec 2021; Accepted: 20 Dec 2021; Available online: 28 Dec 2021

\begin{abstract}
The recent findings revealed that emotional intelligence has a vital influence in creating creativity, but, so far little effort has been done to verify this. Therefore, the current research aimed to examine the impact of emotional intelligence on creating with the mediation role of employee attitudes at selected at Mellat Holding in Kurdistan region of Iraq. A quantitative research method was applied to measure the current study. A random sampling method was applied, 150 questionnaires distributed but only 121 questionnaires were received. The study used four dimensions of emotional intelligence (social awareness, self-management, relationship management, self-awareness) as independent variable, also employee attitude as a mediator and creativity as dependent variable. The findings revealed that emotional intelligence have direct and indirect significant and positive influence on creativity at Mellat Holding. Furthermore, the study suggested to include employee engagement and employee commitment as future studies.
\end{abstract}

Keywords - Emotional Intelligence, Creativity, Mellat Holding, Kurdistan Region of Iraq.

\section{INTRODUCTION}

Creativity is regarded as an important component of human mating intelligence (Ruiz-Ariza, et al., 2019). While not always necessary for survival, creative behaviors allow people to express the inner workings of their minds, providing insights into a variety of aspects of their deeper psychology, such as general intelligence and openness (Ebrahimi, et al., 2018). Humor-related production appears to be particularly important to relationships among the many facets of creativity (including both intimate and nonintimate relationships).

The study of creativity has piqued the interest of professionals and researchers from a wide range of fields, as the concept is regarded as crucial in many situations (Geher, et al., 2017). Recent integrative efforts to describe and delineate the field of creativity research have been made (Salavera, et al., 2017). In terms of definitions, many researchers have adopted Mumford's "new and useful" definition of creativity (Darvishmotevali, et al., 2018), which suggests that a creative product is one that is both novel and useful or adaptable (Ali \& Anwar, 2021). Although creativity can be defined in a few words, the investigation of its underlying causes and mechanisms has resulted in a greater conceptual diversity. Personality traits, cognitive abilities, cognitive styles, and motivation have all been used to express the multifaceted nature of creativity (Neubauer, et al., 2018). In the study of creativity, it is clear that both cognitive and non-cognitive variables must be considered. Personality and emotional aspects appear to play a key role in the latter variables (Batey and Furnham 2006; Sa'nchezRuiz, in press, Ali \& Anwar, 2021, Anwar \& Shukur, 2015). The primary goal of this research is to look into the relationship between creativity and emotion-related personality traits using the trait emotional intelligence (trait EI or trait emotional self-efficacy) framework (Wisetsri, et al., 2021).

There has been a surge in the literature on emotional intelligence (EI), with two contrasting approaches: those that focus on ability and are derived from the original EI conceptualization (with a focus on being able to reason 
validly about emotions) and self-report (trait) measures (which focus on behavioural dispositions and selfperceptions of one's ability to recognize and understand emotions) (Ali \& Anwar, 2021, and Yildırım, et al., 2019). Trait EI, according to empirical research, is more strongly related to, but distinct from, personality as measured by the Big Five (Ali \& Anwar, 2021, and Angela \& Caterina, 2020), and is distinct from ability EI (Dewaele, 2018). The misconception that EI or competencies can be measured through self-report and the potential for faking on selfreport EI measures are highlighted by critics of ability measures of EI (Ali \& Anwar, 2021). In this study, similar criticisms of the measure were used (He, et al., 2018). Others argue that EI, particularly trait EI (Anwar \& Shukur, 2015), is an individual difference construct that exists within the same space as personality (Anwar \& Abd Zebari, 2015) and thus accounts for very little criterion variance beyond that of basic personality dimensions (Silva \& Coelho, 2019). Toyama \& Mauno, (2017), investigate this further and find evidence to suggest that EI is a distinct construct, partly because it is influenced by a number of personality factors and "exists at the lower levels of personality hierarchies", dispelling the myth that EI is simply "rebranded" personality (Gardi,2021).

Furthermore, while much research has focused on the impact of EI on individual behaviors and performance, little has been done to investigate the relationship between EI and creativity (Jafri, 2020). This is regrettable for a number of reasons (Ali \& Anwar, 2021). In the pantheon of character strengths and virtues, both EI and creativity are frequently mentioned (Gheorghe, et al., 2020). Yet, little research has been done to see why and how EI can help people be more creative. Only tangentially included creativity in Bochkova, (2020) conceptualization and subsequent integrative models of EI (Paek, et al., 2020). Mukherjee, et al., (2021) advocated for a greater focus on creative abilities and research into practical knowledge (Ali \& Anwar, 2021). He claimed that EI allows people to navigate their daily lives more effectively and act creatively (Kiani, et al., 2018, and Anwar, 2017), but research on the topic has been slow. The mechanisms by which EI can promote creativity, in particular, remain a mystery (Gupta \& Bajaj, 2017).

In short, people prefer highly humorous individuals as social partners over those who are less amusing. The immediate function of such behavior is to elicit positive affect in others, so humor production has an emotional component to it (Aziz, et al., 2021). As a result, humor production is conceptually linked to emotional intelligence, a broad set of psychological abilities centered on the cognition-emotion interface (Anwar \& Louis, 2017, Ali \& Anwar, 2021, Abdullah, et al., 2017, and Meshkova \& Enikolopov, 2018). In general, previous research has failed to find a significant link between emotional intelligence and creative markers (Nori, et al., 2018). Such past research has not included examined markers of humor production in this realm. We expect emotional intelligence to have a positive relationship with humor production, given how important emotional processing and expression are to all aspects of humor (Ali \& Anwar, 2021). The current study looked at the impact of emotional intelligence on creativity at Mellat Holding, as well as the role of employee attitudes as a mediator (Dehghani, et al., 2019).

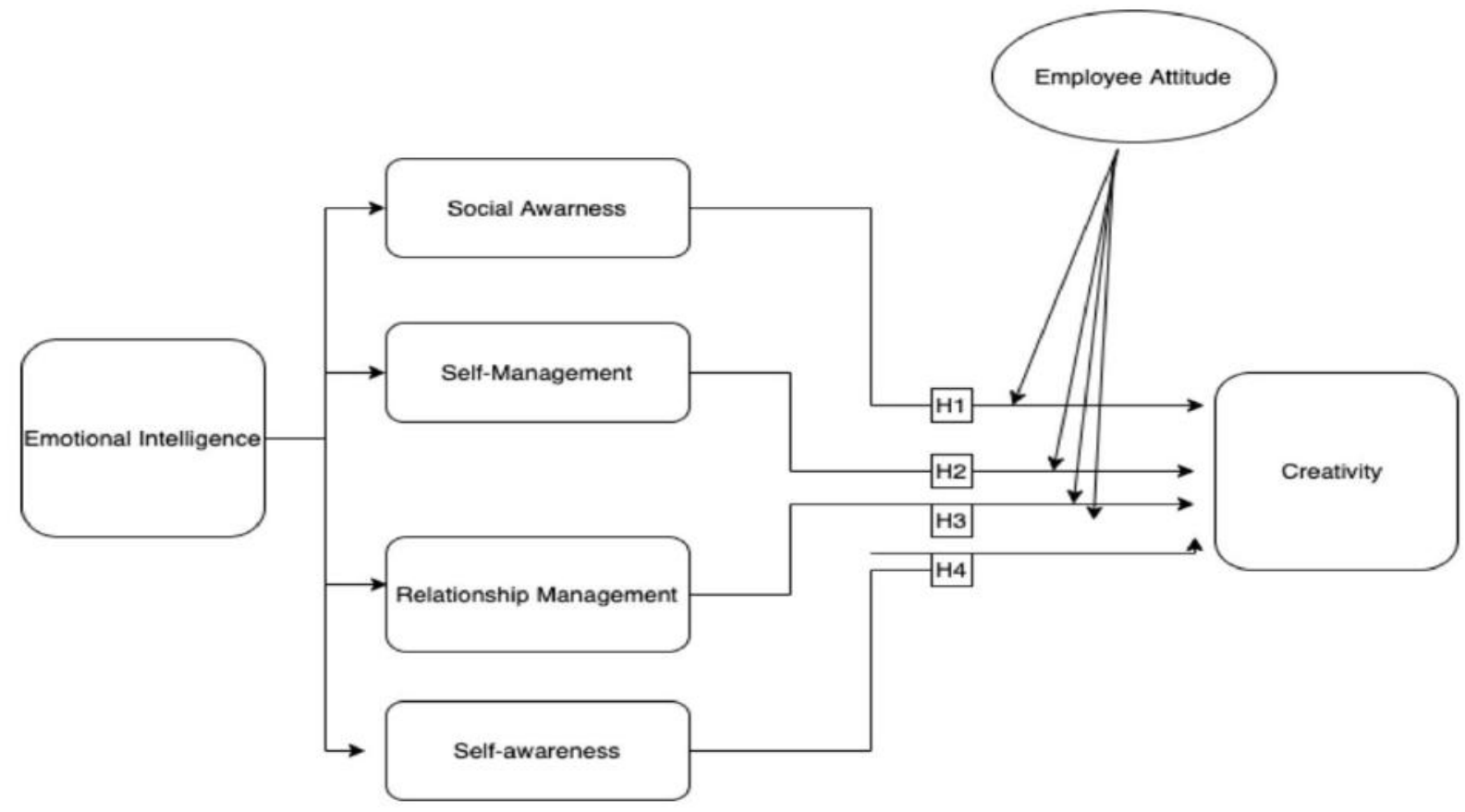

Fig. 1: Research Model

This article can be downloaded from here: www.ijaems.com 


\section{Research Hypotheses:}

H1a: Social awareness as emotional intelligence dimensions has a positive and significant influence on creativity at selected at Mellat Holding.

H1b: Employee attitudes mediates the role of social awareness as emotional intelligence dimensions with creativity at selected at Mellat Holding.

H2a: Self-management as emotional intelligence dimensions has a positive and significant influence on creativity at selected at Mellat Holding.

$\mathrm{H} 2 \mathrm{~b}$ : Employee attitudes mediates the role of selfmanagement as emotional intelligence dimensions with creativity at selected at Mellat Holding.

H3a: Relationship management as emotional intelligence dimensions has a positive and significant influence on creativity at selected at Mellat Holding.

H3b: Employee attitudes mediates the role of relationship management as emotional intelligence dimensions with creativity at selected at Mellat Holding.

H4a: Self-awareness as emotional intelligence dimensions has a positive and significant influence on creativity at selected at Mellat Holding.

H4b: Employee attitudes mediates the role of selfawareness as emotional intelligence dimensions with creativity at selected at Mellat Holding.

\section{LITERATURE REVIEW}

\section{Emotional Intelligence}

Emotional intelligence is defined as the ability to solve problems by using one's thoughts, feelings, and intuition. This also includes the ability to influence others' thinking and actions based on one's own and others' emotions (Dewaele, et al., 2018). There are several emotional intelligence tests available, and these tests have been found to be positively associated with social satisfaction and a variety of other indicators of life success in general (Ahmadi Faqih, et al., 2018). This pattern of findings suggests that emotional intelligence and the ability to handle various social situations are likely linked. In multiple domains, emotional intelligence has been found to predict outcomes such as successful leadership (Ali \& Anwar, 2021, Anwar, K., \& Balcioglu, 2016, Anwar, 2017, Hameed \& Anwar, 2018, and Prayetno, 2020). Our ability to understand the mental states of others is a key feature of emotional intelligence. This phenomenon is known as empathic accuracy, according to one study. It claims that this ability is critical in how humans interact with one another on a variety of levels (Kaplan, 2019). According to the findings of this study, empathic accuracy is comprised of three levels of comprehension: empathic understanding, empathic expression, and empathic communication (Qader, et al., 2021). Each of these is necessary for accurately and positively navigating social situations (Ali \& Anwar, 2021). These aspects of emotional intelligence have been linked to a variety of important life outcomes, as well as personality traits like openness to new experiences (Ali, et al., 2021, Anwar \& Qadir, 2017, Nadaf, et al., 2019). Emotional Intelligence (EI) is a construct that includes four specific competencies: (a) "the ability to accurately perceive, appraise, and express emotion; (b) the ability to access and/or generate feelings when they facilitate thought; (c) the ability to understand emotion and emotional knowledge; and (d) the ability to regulate emotions to promote emotional and intellectual growth" (Anwar \& Abdullah, 2021, Ali \& Anwar, 2021, Anwar, 2017, and Amiri \& Partabian, 2019). It's become a crucial component that companies strive to cultivate at work (Ruiz-Ariza, et al., 2019). Evidence suggests that people's ability to understand and relate to others' emotions, as well as effectively handle them, can lead to more positive member interactions (Ebrahimi, et al., 2018). EI has been linked to positive social interactions; on the other hand, less emotionally intelligent people are more likely to have poor interpersonal relationships, higher aggression, and higher drug and alcohol use (Ali \& Anwar, 2021, Anwar \& Ghafoor, 2017, Geher, et al., 2017). Although this line of research suggests a link between emotional intelligence and positive social interactions with coworkers, little is known about why emotionally intelligent people are more likely to be generous. Generosity is a core human virtue, according to Salavera, et al., (2017). "Notions of shared humanity, of the importance of friendship, of generosity and charitable acts, of giving others pleasure rather than pain (Sabir, et al., 2021)," as Darvishmotevali, et al., (2018) put it, were acknowledged and admired in classical Athenian culture. Giving is a cornerstone of being a good person in both Confucianism and Judaism, where it appears in Pirkei Avot [Ethics of the Fathers] as a cornerstone of being a good person. Prosocial behavior includes acts of generosity. "Behavior that the actor expects to benefit the person or persons to whom it is directed," says the latter (Ali \& Anwar, 2021, Anwar \& Climis, 2017, Anwar \& Louis, 2017, Neubauer, et al., 2018). Generosity (also known as favor exchange) is a key quality of kindness (Sorguli, et al., 2021), which entails assisting others who are unable to obtain resources or complete a task on their own. Favor exchange is an interaction in which resources are exchanged with the expectation of receiving equal resources in return. Favor exchange is defined as a "dyadic interaction in which giving and receiving resources is predicated on the expectation of equitable resources being provided directly 
in return"(Hamza, et al., 2021). Status, service, love, money, information, and goods are among the six types of exchanges identified by Y1ldirım, et al., (2019). These types of interactions, as well as how they are carried out, are crucial in the workplace. Favor exchanges and how they are carried out have a significant impact on how they are perceived and how they affect a person's social status. We believe that emotionally intelligent people are more likely to do more favors for their colleagues and to behave generously (Ali \& Anwar, 2021, Anwar \& Shukur, 2015). Emotionally intelligent people use emotions in such a way that they gain a better understanding of their social surroundings, which allows them to know when and how to act generously. Individuals with a high level of EI, in particular (Abdullah \& Anwar, 2021), can use their ability to appraise and recognize emotions in others (Ismeal, et al., 2021); they can sense others' emotions and anticipate their potential emotional responses. This enables them to recognize when a colleague requires assistance and respond appropriately. This is critical in organizational life because work is highly interdependent, and thus favors like helping behaviors become crucial in completing tasks more effectively. Furthermore (Ali \& Anwar, 2021), because emotionally intelligent people are able to notice and respond to each other's needs, generosity is more likely to be reciprocated. Finally, emotionally intelligent people are capable of developing and maintaining high-quality interpersonal relationships, which reinforces favor exchange engagement (Hamad, et al., 2021). The term emotional intelligence (EI) has been used in psychology and schools from two perspectives: skill (Ali \& Anwar, 2021, Anwar \& Abdullah, 2021, Dewaele, 2018) and a mixed approach. We've all heard of creativity as the ability of some people to create unique and original items. We also believe that it is a faculty that everyone possesses to some degree, but that it can be developed through training and categorized as artistic, literary, scientific, and so on. Convergent thinking is the operation that entails the production of multiple responses or solutions to a single problem; divergent thinking is the operation that entails the production of multiple responses or solutions to a single problem. Angela \& Caterina, (2020) proposed four creativity characteristics or factors for divergent production: fluency, flexibility, originality, and elaboration. By assigning creativity a global skill nature, He, et al., (2018) defined creativity as the process of discovering problems or gaps in information, forming ideas or hypotheses, testing, amending, and communicating the results. Emotional intelligence (EI) as a construct has recently received a lot of attention from academics and practitioners in the workplace (Ali \& Anwar, 2021). EI is viewed as a significant predictor of job success and a necessary component of successful job performance. Since the concept of EI became popular, researchers have been trying to figure out how it relates to a variety of organizationally important variables (Gardi, et al., 2021). However, researchers have largely ignored employee creativity, which is one of the most important issues in organizations. Because there is a lack of research on the relationship between EI and creativity, some researchers have emphasized the need to investigate it. Given the paucity of research on the relationship between EI and employee creativity, it's critical to investigate the link between the two key variables (Qader, et al., 2021). As a result, the current study is a modest attempt to fill this research gap. Furthermore, existing EI research has primarily used a main effects approach in examining the EIoutcome relationship, and has not addressed various individual and contextual variables that can alleviate/aggravate various outcomes. Recent studies in the field of EI have shifted their focus away from direct effects and toward explanatory mechanisms (viz. mediators and moderators) (Hamza, et al., 2021). Intervening variables may mediate and moderate the relationship between EI and work outcomes, according to researchers. Researchers have pointed out that there is a need to explore that how EI can facilitate creativity. The proactive personality (PP) and organizational climate were used as explanatory mechanisms in this study to better understand the relationship between EI and employee creativity (Hamad, et al., 2021). In the current study, it is assumed that PP and organizational climate moderate the impact of EI on employee creativity. As a result, the research is important from two perspectives (Silva \& Coelho, 2019).

\section{Creativity}

A number of emotional characteristics are linked to creativity. Affective disorders are linked to creative achievement in the arts, for example. In samples of eminent artists, the prevalence of affective disorders ranges from 38 percent to 43 percent, compared to 2 percent to $8 \%$ in the general population. Several studies have suggested that the experience of strong positive emotions or mild manic states may be the primary cause of the link between affective disorders and creativity (Hamza, et al., 2021). Positive or hypomanic moods increase awareness and improve thinking breadth and flexibility. People who are in a positive mood make more original word associations and perform better on creative ability tests than people who are in a negative or neutral mood. In addition, students who score higher on trait hypomania describe themselves as unique and creative, and they report participating in more artistic or fantasy activities (Toyama \& Mauno, 2017). In a number of studies, the effects of personality traits on creativity have been shown to vary across domains. The most significant differences were discovered in two emotion-related traits. The first is 
emotional sensitivity, which is linked to the EI Emotionality trait (which includes facets like Emotion perception and Emotion expression). Artists have demonstrated greater sensitivity and emotional expressiveness, as well as a greater interest in internal mental life (Karem, et al., 2021). Emotional instability is the second domain-dependent trait, and it is inversely related to the trait EI Self-control factor (which includes facets like Emotion regulation and Stress management). Artists are more impulsive, anxious, and unable to control their emotions than scientists, according to research (Ali \& Anwar, 2021, Anwar, 2015, Anwar \& Shukur, 2015, Jafri, 2020).

Employee creativity is one of the most pressing human resource issues facing businesses in the twenty-first century. Employees who can "think outside the box" can help the company gain a competitive advantage and deal with the complex challenges of today's fast-changing world. Understanding the dynamics of creativity in organizations has recently become a high priority in organizational behavior research and has piqued the interest of both academics and practitioners. The reason for the interest is that it has a significant impact on organizational effectiveness and survival, as well as on achieving competitive advantages (Gheorghe, et al., 2020).

In literature, there are many different definitions of creativity. Some saw it as a set of personal characteristics, while others saw it as a process. Employee creativity, according to Bochkova, (2020), refers to individuals working together in a complex social system creating valuable, useful new products, services, ideas, procedures, or processes. Paek, et al., (2020) found that creativity meets two criteria: novelty or originality, and potentially relevant for or useful to an organization. Employee creativity has been included as a variable because the employee is at the center of any creative process. Employees must be willing and capable of innovating in order to achieve a continuous flow of innovations. Employee creativity has been linked to both personal factors, as well as their interaction. Individual or person-specific factors-individual abilities (e.g., cognitive capabilities, expertise, relevant task knowledge, necessary technical skills) and willingness (e.g., motivated and satisfied)-have received a lot of attention from researchers in order to better understand employee creativity (Mukherjee, et al., 2021).

\section{Creativity and Emotional Intelligence}

Creativity has been important to determine in the past because it is so subjective. However, the idea of creativity has been studied a lot and can be linked to other things in people's personalities. For example, a study on humor and creativity found that people who liked both positive and negative humor did better than people who only liked one or the other kind of humor. Previous research on creativity has also found that different aspects of emotional intelligence (e.g., emotional facilitation) may be linked to signs of creativity, as well (Kiani, et al., 2018). The relationship between emotional intelligence and indicators of creativity, on the other hand, isn't clear from the wider body of research. It turns out that emotional intelligence isn't linked to markers of emotional creativity, which is the ability to be creative when expressing emotions. A part of this study looked at emotional creativity by having people describe how they would deal with different emotional situations and having their responses judged for signs of creativity. They also found that emotional intelligence was not linked to behavioral creativity (based on tasks such as writing a Haiku that was rated for fluidity and other markers of quality). The goal of this study is to add to the research that shows how markers of emotional intelligence and creativity are linked in the real world. This type of study looks at how well people can read the emotions in other people's faces, which is done by taking a test called "reading the mind in the eyes" (Ali \& Anwar, 2021, Anwar \& Surarchith, 2015, Anwar, 2017, Gupta \& Bajaj, 2017). This test is very well-tested and has been used for a long time to measure how good you are at figuring out what people are feeling from their faces. Because knowing how others feel is so important, it may be that people who are very creative are good at this kind of job. Intelligence and creativity both have mental abilities, but the mental operations that go into these abilities are different. Intelligence is the ability to solve problems that require analytical thinking in response to well-defined tasks. Creative ability refers to originality and fluency of ideas on tasks that aren't set in stone. People who do different kinds of mental operations have different kinds of test responses. People who give high-quality answers on an intelligence test have one or a small group of answers that meet a certain standard of correctness or goodness. This is an example: One subtest on the WAIS looks for similarities between objects that people know. For example, an orange and a banana are both fruits. The test manual has a small number of answers that are correct. For example, both an orange and a banana are fruits, and both are fruits. On the other hand, high-quality answers to tests of creative ability include a lot of ideas that are also unique. If you look at Meshkova \& Enikolopov, (2018) tests, for example, they have a subtest like the Similarities on the WAIS. One item asks how are milk and meat alike. Most people think milk and meat come from animals. An original and high-creativity answer would be that they have been checked by the government. Theoretical models have tried to explain how intelligence and creativity work together. These include thinking of creativity as a subset of intelligence, thinking of creativity 
and intelligence as related or partially overlapping, and thinking of creativity and intelligence as separate or separate constructs (Ali \& Anwar, 2021, Anwar \& Shukur, 2015). There is some support for each of the proposed theoretical models. People who support each model, however, have different definitions of what creativity is. When ratings of real-life professional achievement are used to measure creativity, over the whole range of creativity and intelligence, the correlation between the two is about.40, which supports the idea that some of the constructs overlap (Nori, et al., 2018). Dehghani, et al., (2019) stated that this correlation is caused by a social structure that makes it easier for people to show their creativity in jobs that require a lot of education (e.g., in science). When performance tests are used to measure creativity, the correlation between the two is much lower, which supports the idea that the two are separate things. As an example, there were 388 correlations looked at (Anwar \& Shukur, 2015). The correlation between intelligence and creative ability ranged from.06 to 0.21 in this study, which looked at 388 correlations. Intelligence and creativity have also been looked at in terms of how people act when they are creative. Only a small amount of intelligence is linked to a person's ability to be creative, with are from.05 to.30. Even though creative artists and scientists have more intelligence than the average person, above a certain level, intelligence doesn't play a big role in how well they do. Tests of creativity are better at predicting what people will do in the real world, with correlations ranging from.22 to.53, than they are at predicting what people will do. Employee creativity is one of the most important factors in a company's success, especially in the modern business world (Ali \& Anwar, 2021). Studies on EI and creativity aren't very many. According to the researcher, there were only a few studies that looked at how the two concepts in the study were linked to each other. People who say that EI does help employees be more creative think that EI helps people be able to separate emotions and make good decisions about how to think and act. Emotions help people think, which helps them think about different ways of looking at a problem, which leads to new ideas. People who took the Swinburne University Emotional Intelligence Test (SUEIT) also had a better chance of being creative at work (Anwar, 2016). However, this relationship isn't the same in all of the studies that looked at it. Some researchers said that there is no connection between EI and creativity. Divergent thinking and creative personality are two indicators of creativity in a study by Dewaele, et al., (2018) that looked at the relationship between the EI and creativity in Spanish university students. They found that the ability EI had little to do with either of these indicators of creativity. Thus, there is a contradiction in the literature about how the two variables are linked. People who did this research (Ahmadi Faqih, et al., 2018) said that EI and creativity are linked. We agreed with them. We agreed with them because we thought that employees' EI skills could affect their creativity. As part of the ability model, one of the parts of EI is the use of emotion that helps people with cognitive activities like reasoning, decision-making, problem-solving, and creativity (Prayetno, 2020).

\section{METHODOLOGY}

\section{Research Design}

Research design is a significant approach that supports and guides to gather information and analyzing stage. Moreover, it proposes the plan and the form of research that requires the type of information to be collected, its basis and its method of collection. In addition, it explains and indicates the type of information to be used to dissect the research, as well as the type of exploration strategies that the researcher will use to inspect the relationship or effect of the factors. In addition, it is stated that this method involves introducing and delimiting the result and the survey result that are considered reliable. In addition, it is an arranged for realization diagram that governs as a link between research questions and use. The exploration settings examine the measured values for the driving test, the exchange of time for the information range and how the information will be collected. It is about explaining and looking at an experimental evidence system that will be used to investigate the speculations created by the researcher and to find the correct answer to the investigations created by the specialist. In this research, the reasons why the researcher used the quantitative approach; it uses factual data as an effective instrument and less effort and assets. In addition, another explanation that the analyst applied this strategy to the quantitative technique is the best way to handle the meter and the inspection between factors.

\section{Sample Size and Sampling Method}

The sample is intended to be a part and the attributes, the researcher therefore resorts to a sample study of society that can be used to study all the units of the SMEs the researcher used in this study two types of samples: Simple random sample. A random sampling method was applied, 150 questionnaires distributed but only 121 questionnaires were received. The sample represents $29 \%$ of the total study population, and a random drawing was made to ensure that all elements of the sample at Mellat Holding have the same chance.

\section{Data collection}

As noted in the previous section, the study implemented a quantitative method using a questionnaire to examine the 
current study. A questionnaire is a set of many questions to be asked to the participants based on their perspective and prior knowledge of the Mellat Holding. This method is often used to gather knowledge about specific research. The study adopted a questionnaire from various academic articles.

\section{RESULTS}

Measuring first research hypothesis (H1a)

Direct influence of social awareness as emotional intelligence dimensions has a positive and significant influence on creativity at selected at Mellat Holding.

Table 1: Reliability analysis (H1a)

\begin{tabular}{|c|c|c|}
\hline & Reliability statistics & N of items \\
\hline Variables & Cronbach Alpha & 9 \\
\hline Social Awareness & .791 & 7 \\
\hline creativity & .756 & 7 \\
\hline Employee attitude & .789 & \\
\hline
\end{tabular}

The study applied reliability analysis to measure each variable used to measure direct influence of social awareness as emotional intelligence dimensions has a positive and significant influence on creativity at selected at Mellat Holding. The result revealed that the value of Cronbach alpha for social awareness as independent variable was .791 for nine items this indicated that all items used to measure social awareness as dimension of emotional intelligence were reliable, the value of Cronbach alpha for creativity as dependent variable was .756 for seven items this indicated that all items used to creativity were reliable, and the value of Cronbach alpha for employee attitude as mediator variable was .789 for seven items this indicated that all items used to measure employee attitude were reliable.

Table 2: Regression Analysis between social awareness and emotional intelligence

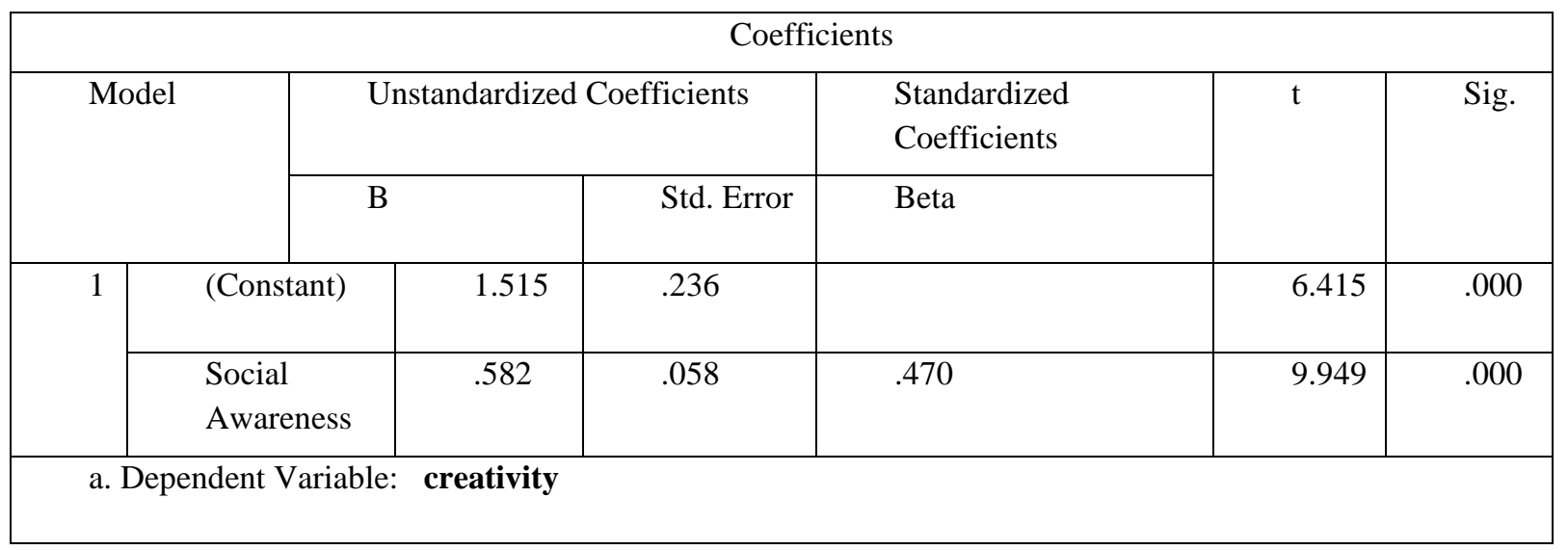

Table (2), shows the results of a simple regression analysis, which was used to measure the direct relationship between social awareness and creativity. The results showed the value of Beta. 470 and B values are. 582, these showed that there is a strong relationship between social awareness and creativity. 


\section{Measuring first research hypothesis (H1)}

Indirect influence of employee attitudes as a mediator role between social awareness as emotional intelligence dimensions and creativity at selected at Mellat Holding.

Table 3: Sobel test to measure (H1B)

\begin{tabular}{|c|c|c|c|c|c|}
\hline & Input: & & Test statistic: & Std. Error: & $p$-value: \\
\hline$a$ & .582 & Sobel test: & 2.37370032 & 0.04732105 & 0.01761084 \\
\hline$b$ & .193 & Aroian test: & 2.36265046 & 0.04754237 & 0.01814477 \\
\hline$s_{a}$ & .058 & Goodman test: & 2.38490667 & 0.0470987 & 0.01708345 \\
\hline & .079 & Reset all & \multicolumn{3}{|c|}{ Calculate } \\
\hline
\end{tabular}

The Sobel test is basically a specialized t test that provides a method to determine whether the reduction in the effect of the independent variable, after including the mediator in the model, is a significant reduction and therefore whether the mediation effect is statistically significant. The Sobel test is used to determine whether a variable carries (or mediates) the effect of an independent variable to the dependent variable - the outcome of interest. A significant test statistic offers evidence that an independent variable has an indirect effect. As we can see in the above table, the P-value to measure the relationship between social awareness and employee attitudes is .0 .176 and the P-value to measure the relationship between employee attitude and creativity is .0018 this indicated that both $\mathrm{P}$-value are greater than 0.05 this concluded that employee attitudes have a significant role in mediating social awareness as emotional intelligence dimensions and creativity at selected at Mellat Holding.

\section{Measuring second research hypothesis (H2a)}

Direct influence of Self-management as emotional intelligence dimensions has a positive and significant influence on creativity at selected at Mellat Holding.

Table 4: Reliability analysis (H2)

\begin{tabular}{|l|l|l|}
\hline \multicolumn{2}{|c|}{ Reliability statistics } \\
\hline Variables & Cronbach Alpha & N of items \\
\hline Self-management & .765 & 6 \\
\hline Creativity & .746 & 7 \\
\hline Employee Attitude & .789 & 7 \\
\hline
\end{tabular}

The study applied reliability analysis to measure each variable used to measure direct influence of Selfmanagement as emotional intelligence dimensions has a positive and significant influence on creativity at selected at Mellat Holding. The result revealed that the value of Cronbach alpha for Self-management as independent variable was .765 for six items this indicated that all items used to measure Self-management as dimension of emotional intelligence were reliable, the value of Cronbach alpha for creativity as dependent variable was .746 for seven items this indicated that all items used to creativity were reliable, and the value of Cronbach alpha for employee attitude as mediator variable was .789 for seven items this indicated that all items used to measure employee attitude were reliable. 
Table 5: Regression Analysis between Self-management and emotional intelligence

\begin{tabular}{|c|c|c|c|c|c|}
\hline \multicolumn{6}{|c|}{ Coefficients } \\
\hline \multirow[t]{2}{*}{ Model } & \multicolumn{2}{|c|}{$\begin{array}{l}\text { Unstandardized } \\
\text { Coefficients }\end{array}$} & $\begin{array}{l}\text { Standardized } \\
\text { Coefficients }\end{array}$ & \multirow[t]{2}{*}{$\mathrm{t}$} & \multirow[t]{2}{*}{ Sig. } \\
\hline & B & Std. Error & Beta & & \\
\hline (Constant) & 3.403 & .120 & & 28.278 & .000 \\
\hline Self-management & .124 & .030 & .217 & 4.155 & .000 \\
\hline
\end{tabular}

Table (5) shows the results of the simple regression analysis used to measure the ratio of Self-management to creativity. The results showed that the value of Beta. 217, and the value of is. 124 showed these that there is a strong link between the Selfmanagement and creativity.

\section{Measuring second research hypothesis (H2b)}

Indirect influence of employee attitudes as a mediator role between Self-management as emotional intelligence dimensions and creativity at selected at Mellat Holding.

Table 6: Sobel test to measure (H2B)

\begin{tabular}{|c|c|c|c|c|c|}
\hline & Input: & & Test statistic: & Std. Error: & $p$-value: \\
\hline$a$ & .124 & Sobel test: & 3.95619687 & 0.0226925 & 0.00007615 \\
\hline$b$ & .724 & Aroian test: & 3.94652119 & 0.02274814 & 0.00007929 \\
\hline$s_{\mathrm{a}}$ & .030 & Goodman test: & 3.96594408 & 0.02263673 & 0.00007311 \\
\hline & .053 & Reset all & \multicolumn{3}{|c|}{ Calculate } \\
\hline
\end{tabular}

The Sobel test is basically a specialized t test that provides a method to determine whether the reduction in the effect of the independent variable, after including the mediator in the model, is a significant reduction and therefore whether the mediation effect is statistically significant. The Sobel test is used to determine whether a variable carries (or mediates) the effect of an independent variable to the dependent variable - the outcome of interest. A significant test statistic offers evidence that an independent variable has an indirect effect. As we can see in the above table, the P-value to measure the relationship between self-management and employee attitudes is .0 .0076 and the P-value to measure the relationship between employee attitude and creativity is .00073 this indicated that both P-value are greater than 0.05 this concluded that employee attitudes have a significant role in mediating self-management as emotional intelligence dimensions and creativity at selected at Mellat Holding.

\section{Measuring third research hypothesis (H3a)}

Direct influence of Relationship management as emotional intelligence dimensions has a positive and significant influence on creativity at selected at Mellat Holding.

Table 7: Reliability analysis $(\mathrm{H} 3 \mathrm{a})$

\begin{tabular}{|c|c|c|}
\hline \multicolumn{2}{|c|}{ Reliability statistics } \\
\hline Variables & Cronbach Alpha & N of items \\
\hline Relationship Management & .743 & 7 \\
\hline Creativity & .756 & 7 \\
\hline Employee Attitudes & .789 & 7 \\
\hline
\end{tabular}

The study applied reliability analysis to measure each variable used to measure direct influence of relationship This article can be downloaded from here: www.ijaems.com

C2021 The Author(s). Published by Infogain Publication. management as emotional intelligence dimensions has a positive and significant influence on creativity at selected at

This work is licensed under a Creative Commons Attribution 4.0 License. http://creativecommons.org/licenses/by/4.0/ 
Mellat Holding. The result revealed that the value of Cronbach alpha for relationship management as independent variable was .743 for seven items this indicated that all items used to measure relationship management as dimension of emotional intelligence were reliable, the value of Cronbach alpha for creativity as dependent variable was
.756 for seven items this indicated that all items used to creativity were reliable, and the value of Cronbach alpha for employee attitude as mediator variable was .789 for seven items this indicated that all items used to measure employee attitude were reliable.

Table 8: Regression Analysis between relationship management and emotional intelligence

\begin{tabular}{|c|c|c|c|c|c|c|}
\hline & \multicolumn{6}{|c|}{ Coefficients } \\
\hline & \multirow[t]{2}{*}{ Model } & \multicolumn{2}{|c|}{$\begin{array}{l}\text { Unstandardized } \\
\text { Coefficients }\end{array}$} & \multirow{2}{*}{$\begin{array}{l}\text { Standardized } \\
\text { Coefficients } \\
\text { Beta }\end{array}$} & \multirow[t]{2}{*}{$\mathrm{t}$} & \multirow[t]{2}{*}{ Sig. } \\
\hline & & $\mathrm{B}$ & Std. Error & & & \\
\hline \multirow[t]{2}{*}{1} & (Constant) & 3.216 & .192 & & 16.740 & .000 \\
\hline & $\begin{array}{l}\text { Relationship } \\
\text { management }\end{array}$ & .159 & .048 & .175 & 3.329 & .001 \\
\hline
\end{tabular}

Table (8), shows the results of a simple regression analysis, which was used to measure the direct relationship between relationship management and creativity. The results showed the value of Beta. 159 and $B$ values are. 175, these showed that there is a strong relationship between relationship management and creativity.

\section{Measuring third research hypothesis $(\mathrm{H} 3 \mathrm{~b})$}

Indirect influence of employee attitudes mediates the role of relationship management as emotional intelligence dimensions with creativity at selected at Mellat Holding.

Table 9: Sobel test to measure (H3B)

\begin{tabular}{|c|c|c|c|c|c|}
\hline & Input: & & Test statistic: & Std. Error: & $p$-value: \\
\hline a & .159 & Sobel test: & 3.23377054 & 0.0278786 & 0.00122168 \\
\hline$b$ & .567 & Aroian test: & 3.22687139 & 0.02793821 & 0.00125152 \\
\hline$s_{a}$ & .048 & Goodman test: & 3.24071412 & 0.02781887 & 0.00119231 \\
\hline$s_{\mathrm{b}}$ & .038 & Reset all & \multicolumn{3}{|c|}{ Calculate } \\
\hline
\end{tabular}

The Sobel test is basically a specialized t test that provides a method to determine whether the reduction in the effect of the independent variable, after including the mediator in the model, is a significant reduction and therefore whether the mediation effect is statistically significant. The Sobel test is used to determine whether a variable carries (or mediates) the effect of an independent variable to the dependent variable - the outcome of interest. A significant test statistic offers evidence that an independent variable has an indirect effect. As we can see in the above table, the P-value to measure the relationship between relationship management and employee attitudes is .0.012 and the P-value to measure the relationship between employee attitude and creativity is .011 this indicated that both P-value are greater than 0.05 this concluded that employee attitudes have a significant role in mediating relationship management as emotional intelligence dimensions and creativity at selected at Mellat Holding. 


\section{Measuring fourth research hypothesis (H14a)}

Direct influence of self-awareness as emotional intelligence dimensions has a positive and significant influence on creativity at selected at Mellat Holding.

Table 10: Reliability analysis (H4a)

\begin{tabular}{|c|c|c|}
\hline \multicolumn{2}{|c|}{ Reliability statistics } \\
\hline Variables & Cronbach Alpha & N of items \\
\hline Self-Awareness & .765 & 7 \\
\hline Creativity & .756 & 7 \\
\hline Employee Attitude & .789 & 6 \\
\hline
\end{tabular}

The study applied reliability analysis to measure each variable used to measure direct influence of self-awareness as emotional intelligence dimensions has a positive and significant influence on creativity at selected at Mellat Holding. The result revealed that the value of Cronbach alpha for self-awareness as independent variable was .765 for six items this indicated that all items used to measure self-awareness as dimension of emotional intelligence were reliable, the value of Cronbach alpha for creativity as dependent variable was .756 for seven items this indicated that all items used to creativity were reliable, and the value of Cronbach alpha for employee attitude as mediator variable was .789 for seven items this indicated that all items used to measure employee attitude were reliable.

Table 11: Regression Analysis between self-awareness and emotional intelligence

\begin{tabular}{|c|c|c|c|c|c|c|}
\hline \multicolumn{7}{|c|}{ Coefficients } \\
\hline \multirow{2}{*}{\multicolumn{2}{|c|}{ Model }} & \multicolumn{2}{|c|}{$\begin{array}{l}\text { Unstandardized } \\
\text { Coefficients }\end{array}$} & $\begin{array}{l}\text { Standardized } \\
\text { Coefficients }\end{array}$ & \multirow[t]{2}{*}{$\mathrm{t}$} & \multirow[t]{2}{*}{ Sig. } \\
\hline & & $\mathrm{B}$ & Std. Error & Beta & & \\
\hline \multirow[t]{2}{*}{1} & (Constant) & 3.403 & .120 & & 28.278 & .000 \\
\hline & self- awareness & .124 & .030 & .217 & 4.155 & .000 \\
\hline
\end{tabular}

Table (11), shows the results of a simple regression analysis, which was used to measure the direct relationship between selfawareness and creativity. The results showed the value of Beta. 124 and B values are. 217, these showed that there is a strong relationship between self- awareness and creativity.

\section{Measuring fourth research hypothesis (H4b)}

Indirect influence of employee attitudes mediates the role of self-awareness as emotional intelligence dimensions with creativity at selected at Mellat Holding.

Table 12: Sobel test to measure (H4B)

\begin{tabular}{|c|c|c|c|c|c|}
\hline & Input: & & Test statistic: & Std. Error: & $p$-value: \\
\hline$a$ & .124 & Sobel test: & 3.82555269 & 0.02226815 & 0.00013048 \\
\hline$b$ & .687 & Aroian test: & 3.80960004 & 0.0223614 & 0.00013919 \\
\hline$s_{\mathrm{a}}$ & .030 & Goodman test: & 3.84170744 & 0.02217452 & 0.00012218 \\
\hline & .068 & Reset all & \multicolumn{3}{|c|}{ Calculate } \\
\hline
\end{tabular}

The Sobel test is basically a specialized t test that provides a method to determine whether the reduction in the effect of the independent variable, after including the mediator in the model, is a significant reduction and therefore whether the This article can be downloaded from here: www.ijaems.com

(C)2021 The Author(s). Published by Infogain Publication. mediation effect is statistically significant. The Sobel test is used to determine whether a variable carries (or mediates) the effect of an independent variable to the dependent variable - the outcome of interest. A significant test statistic

This work is licensed under a Creative Commons Attribution 4.0 License. http://creativecommons.org/licenses/by/4.0/ 
offers evidence that an independent variable has an indirect effect. As we can see in the above table, the P-value to measure the relationship between self-awareness and employee attitudes is .0 .0013 and the P-value to measure the relationship between employee attitude and creativity is 0.0012 this indicated that both $\mathrm{P}$-value are greater than 0.05 this concluded that employee attitudes have a significant role in mediating self-awareness as emotional intelligence dimensions and creativity at selected at Mellat Holding.

\section{CONCLUSION}

In organizational settings, employee attitudes are prevalent as work become more and more interdependent. People who are high on EI and concretize this by helping others through generous behaviors will feel vigorous and are likely to display a higher level of creativity. As shown in research on favor exchange (e.g., Flynn, 2003), member-member exchange is a more common occurrence than leadermember exchange. Within the workplace where favor exchange is promoted among peers and leaders, this can help members to develop a sense of vigor, and thus result in a higher level of engagement in the creative process. These qualities may create higher quality relationships between members within organizational settings. Our study provides insights into how Emotional Intelligence and creativity are mediated by employee attitudes. The findings revealed that emotional intelligence have direct and indirect significant and positive influence on creativity in selected SMEs. Furthermore, the study suggested to include employee engagement and employee commitment as future studies.

\section{REFERENCES}

[1] Ahmadi Faqih, M., Zhargam Hajebi, M., Monirpour, N., \& Motevalli, S. (2018). The Role of Emotional Intelligence Components Teachers (Composition Class) in Predicting Creativity Aspects of (Writing) of Students. The Journal of Research in Humanities, 25(2), 87-109.

[2] Wisetsri, W., Tan, C. H., Gardi, B., Kankaew, K., Kaur, H., \& Pentang, J. (2021). Interplay of Personal Attitudinal Constructs towards online fashion products, Consumer Decision-Making and Image Branding: The Case of Online Fashion Products in Thailand in COVID 19 Pandemic. Studies of Applied Economics, 39(12).

[3] Ali, B. J., \& Anwar, G. (2021). The Effect of Marketing Culture Aspects of Healthcare Care on Marketing Creativity. Ali, BJ, \& Anwar, G.(2021). The Effect of Marketing Culture Aspects of Healthcare Care on Marketing Creativity. International Journal of English Literature and Social Sciences, 6(2), 171-182.

[4] Gardi, B. (2021). The effects of computerized accounting system on auditing process: a case study from northern Iraq. Available at SSRN 3838327.
[5] Amiri, M., \& Partabian, A. (2019). The Relationship between Components of Emotional Intelligence and Students' Creativity in Payame Noor University and the Moderating Role of Gender, Age and Education. Higher Education Letter, 11(44), 213-237.

[6] Aziz, H. M., Sorguli, S., Hamza, P. A., Sabir, B. Y., Qader, K. S., Ismeal, B. A., ... \& Gardi, B. (2021). Factors affecting International Finance Corporation. Journal of Humanities and Education Development (JHED), 3(3), 148-157.

[7] Ali, B. J., \& Anwar, G. (2021). An Empirical Study of Employees' Motivation and its Influence Job Satisfaction. Ali, BJ, \& Anwar, G.(2021). An Empirical Study of Employees' Motivation and its Influence Job Satisfaction. International Journal of Engineering, Business and Management, 5(2), 21-30.

[8] Angela, F. R., \& Caterina, B. (2020). Creativity, emotional intelligence and coping style in intellectually gifted adults. Current Psychology, 1-7.

[9] Bochkova, M. N. (2020). Emotional Iintelligence and Creativity: Relation and Interaction on the Example of Different Categories of Convicts. Psychology and Law, 10(1), 92-102.

[10] Qader, K. S., Ismeal, B. A., Aziz, H. M., Hamza, P. A., Sorguli, S., Sabir, B. Y., ... \& Gardi, B. (2021). The Effect of Human Resources Management Skills on Accounting Information Quality in Kurdistan Public Sector. Journal of Humanities and Education Development (JHED), 3(3), 131143.

[11] Anwar, G., \& Shukur, I. (2015). The Impact of Training and Development on Job Satisfaction: A Case Study of Private Banks in Erbil. International Journal of Social Sciences \& Educational Studies, 2(1), 65.

[12] Ali, B. J., \& Anwar, G. (2021). Strategic leadership effectiveness and its influence on organizational effectiveness. International Journal of Electrical, Electronics and Computers, 6(2).

[13] Darvishmotevali, M., Altinay, L., \& De Vita, G. (2018). Emotional intelligence and creative performance: Looking through the lens of environmental uncertainty and cultural intelligence. International Journal of Hospitality Management, 73, 44-54.

[14] Sabir, B. Y., Qader, K. S., Hamza, P. A., Ali, B., Ismeal, S. S., Aziz, H. M., ... \& Anwar, G. (2021). Analysis of Accounting-Based Measures of Expected Returns: A Study of Private SME In Kurdistan.

[15] Ali, B. J., \& Anwar, G. (2021). Factors Influencing the Citizens' Acceptance of Electronic Government. International journal of Engineering, Business and Management (IJEBM), 5.

[16] Dehghani, Y., Afshin, S. A., S Hoseini, F., \& Saede, M. (2019). The mediating role of Academic Self-Efficacy in the relationship between Emotional Intelligence, Creativity and Achievement Motivation. Journal of School Psychology, 8(2), 22-42.

[17] Sorguli, S., Hamza, P. A., Ismeal, B. A., Sabir, B. Y., Aziz, H. M., Qader, K. S., ... \& Gardi, B. (2021). Adaption of EFilling of Income Tax Returns in Kurdistan. 
[18] Ali, B. J., \& Anwar, G. (2021). Marketing Strategy: Pricing strategies and its influence on consumer purchasing decision. Ali, BJ, \& Anwar, G.(2021). Marketing Strategy: Pricing strategies and its influence on consumer purchasing decision. International journal of Rural Development, Environment and Health Research, 5(2), 26-39.

[19] Anwar, G., \& Abd Zebari, B. (2015). The Relationship between Employee Engagement and Corporate Social Responsibility: A Case Study of Car Dealership in Erbil, Kurdistan. International Journal of Social Sciences \& Educational Studies, 2(2), 45.

[20] Dewaele, J. M. (2018). The relationship between trait emotional intelligence and experienced ESL/EFL teachers' love of English, attitudes towards their students and institution, self-reported classroom practices, enjoyment and creativity. Chinese Journal of Applied Linguistics, 41(4), 468-487.

[21] Hamza, P. A., Sabir, B. Y., Qader, K. S., Aziz, H. M., Ismeal, B. A., Sorguli, S., ... \& Anwar, G. (2021). Global financial markets: Factors influencing the global financial markets.

[22] Ali, B. J., \& Anwar, G. (2021). Self-Leadership Skills as Intangible Resources for Sustainable Competitive Advantage. Advanced Engineering Science, 46(1).

[23] Anwar, G., \& Shukur, I. (2015). The Impact of Service Quality Dimensions on Students' Satisfaction. International Journal of Social Sciences \& Educational Studies, 76.

[24] Dewaele, J. M., Gkonou, C., \& Mercer, S. (2018). Do $\mathrm{ESL} / \mathrm{EFL}$ teachers' emotional intelligence, teaching experience, proficiency and gender affect their classroom practice?. In Emotions in second language teaching (pp. 125-141). Springer, Cham.

[25] Ismeal, B. A., Aziz, H. M., Sorguli, S., Qader, K. S., Sabir, B. Y., Hamza, P. A., ... \& Anwar, G. (2021). The Role of External Auditing in Reducing Creative Accounting Practices.

[26] Ali, B. J., \& Anwar, G. (2021). Employee Turnover Intention and Job Satisfaction. Ali, BJ, \& Hamad, H. A., Qader, K. S., Gardi, B., Abdalla, P., Hamza, D., \& Anwar, G. (2021). The essential variables to consider before investing in financial markets during Covid-19.

[27] Anwar, G.(2021). Employee Turnover Intention and Job Satisfaction. International Journal of Advanced Engineering, Management and Science, 7(6), 22-30.

[28] Gardi, B., Hamza, P. A., Qader, K. S., Anwar, H., Hamad, D., \& Anwar, G. (2021). Factors affecting the quality of financial statements on investment decision making.

[29] Anwar, K. (2017). Analyzing The Conceptual Model Of Service Quality And Its Relationship With Guests'satisfaction: A Study Of Hotels In Erbil. The International Journal of Accounting and Business Society, 25(2), 1-16.

[30] Ebrahimi, M. R., Heydarnejad, T., \& Najjari, H. (2018). The interplay among emotions, creativity and emotional intelligence: A case of Iranian EFL teachers. Int. J. Engl. Lang. Transl. Stud, 6, 90-98.
[31] Qader, K. S., Hamad, H. A., Gardi, B., Abdalla, P., Hamza, D., \& Anwar, G. (2021). The role of sophisticated accounting system in organizational planning.

[32] Anwar, K., \& Louis, R. (2017). Factors Affecting Students' Anxiety in Language Learning: A Study of Private Universities in Erbil, Kurdistan. International Journal of Social Sciences \& Educational Studies, 4(3), 160.

[33] Geher, G., Betancourt, K., \& Jewell, O. (2017). The link between emotional intelligence and creativity. Imagination, Cognition and Personality, 37(1), 5-22.

[34] Hamza, P. A., Hamad, H. A., Qader, K. S., Gardi, B., \& Anwar, G. (2021). Management of outsourcing and its relationship with hotels' performance: An empirical analysis of selected hotels in Erbil. International Journal of Advanced Engineering Research and Science, 8, 10.

[35] Ali, B. J., \& Anwar, G. (2021). Real Estates Strategies: Analysis of Strategic Management Practices in Real Estate Companies. Ali, BJ, \& Anwar, G.(2021). Real Estates Strategies: Analysis of Strategic Management Practices in Real Estate Companies. International Journal of Rural Development, Environment and Health Research, 5(3), 3548.

[36] Abdullah, M. S., Toycan, M., \& Anwar, K. (2017). The cost readiness of implementing e-learning. Custos $\mathrm{E}$ Agronegocio On Line, 13(2), 156-175.

[37] Gheorghe, A., Fodor, O., \& Pavelea, A. (2020). Ups and downs on the roller coaster of task conflict: the role of group cognitive complexity, collective emotional intelligence and team creativity. Psihologia Resurselor Umane, 18(1), 23-37.

[38] Gupta, R., \& Bajaj, B. (2017). The relationship between leader's emotional intelligence and employee creativity: A conceptual framework of mechanism. Procedia computer science, 122, 471-477.

[39] Hamad, H. A., Hamza, P. A., Gardi, B., Saeed, K., Qader, D., \& Anwar, G. (2021). The influence of accounting software in minimizing business costs.

[40] Ali, B. J., \& Anwar, G. (2021). Administrative Crisis: The Role of Effective Leadership Styles in Crisis Management. Ali, BJ, \& Anwar, G.(2021). Administrative Crisis: The Role of Effective Leadership Styles in Crisis Management. International Journal of Advanced Engineering, Management and Science, 7(6), 31-41.

[41] Hamza, P. A., Qader, K. S., Gardi, B., Hamad, H. A., \& Anwar, G. (2021). Analysis the impact of Information technology on Efficient tax Management. International Journal of Advanced Engineering, Management and Science, 7(9), 31-41.

[42] Anwar, K., \& Balcioglu, H. (2016). The relationship between transformational leadership characteristics and effectiveness: A case study of construction companies in Erbil. International Journal of Science Technology and Management, 5(2), 250-256.

[43] He, L., Mao, Y., Sun, J., Zhuang, K., Zhu, X., Qiu, J., \& Chen, X. (2018). Examining brain structures associated with emotional intelligence and the mediated effect on trait creativity in young adults. Frontiers in psychology, 9, 925.

[44] Ali, B. J., \& Anwar, G. (2021). Corporate Social Responsibility: The Influence of Employee Engagement on 
Corporate Social Responsibility. Journal of Humanities and Education Development (JHED), 3(3), 77-83.

[45] Jafri, M. H. (2020). Moderating role of emotional intelligence on personality-employee creativity relationship. Management and Labour Studies, 45(1), 1530 .

[46] Karem, L. E., Hamad, H. A., Bayz, H. A., Fatah, N. A., Ali, D. J., Ahmed, Z. N., ... \& Qader, K. S. (2021). Corporate Governance And Its Effect On Firm Performance In An Emerging Economy. International Journal of Environmental, Sustainability, and Social Science, 2(3), 281-291.

[47] Anwar, K. (2017). Leading Construction Project Teams: The Effectiveness of Transformational Leadership in Dynamic Work Environments in Kurdistan. International Journal of Advanced Engineering, Management and Science, 3(10), 239925.

[48] Hameed, A. A., \& Anwar, K. (2018). Analyzing the Relationship between Intellectual Capital and Organizational Performance: A Study of Selected Private Banks in Kurdistan. International Journal of Social Sciences \& Educational Studies, 4(4), 39.

[49] Ali, B. J., Anwer, R. N. A. D., \& Anwar, G. (2021). Private Hospitals' Service Quality Dimensions: The impact of Service Quality Dimensions on patients' satisfaction. Int. J. Med. Phar. Drug Re, 7.

[50] Anwar, K., \& Qadir, G. H. (2017). A Study of the Relationship between Work Engagement and Job Satisfaction in Private Companies in Kurdistan. International Journal of Advanced Engineering, Management and Science, 3(12), 239944.

[51] Ali, B. J., \& Anwar, G. (2021). Stock Exchange Investment: A Study of Factors That Influence Stock Exchange Investment. Ali, BJ, \& Anwar, G.(2021). Stock Exchange Investment: A Study of Factors That Influence Stock Exchange Investment. International Journal of Engineering, Business and Management, 5(3), 39-46.

[52] Anwar, G., \& Abdullah, N. N. (2021). A Project Management Improvement Program: Enhancing Production With Implementing the Knowledge Management Principles. Advanced Engineering Science, 46(1).

[53] Kaplan, D. E. (2019). Creativity in education: Teaching for creativity development. Psychology, 10(2), 140-147.

[54] Ali, B. J., \& Anwar, G. (2021). The mediation role of change management in employee development. Ali, BJ, \& Anwar, G.(2021). The Mediation Role of Change Management in Employee Development. International Journal of English Literature and Social Sciences, 6(2), 361-374.

[55] Anwar, K. (2017). Factors affecting stock exchange investment in kurdistan. The International Journal of Accounting and Business Society, 25(1), 32-37.

[56] Ali, B. J., \& Anwar, G. (2021). Work Engagement: How Does Employee Work Engagement influence Employee Satisfaction?. Ali, BJ, \& Anwar, G.(2021). Work Engagement: How Does Employee Work Engagement influence Employee Satisfaction, 10-21.

[57] Kiani, A., Kiani, S., Mokhtari, R., \& Shirmohammadi, N. (2018). The Relationship Between Stressful Behaviors With
Emotional Regulation, Emotional Intelligence And Emotional Creativity In Students. Nursing And Midwifery Journal, 16(3), 177-187.

[58] Anwar, K., \& Ghafoor, C. (2017). Knowledge management and organizational performance: A study of private universities in Kurdistan. International Journal of Social Sciences \& Educational Studies, 4(2), 53.

[59] Meshkova, N., \& Enikolopov, S. (2018). Creativity and Deviance: Communication and Interaction. Psychology. Journal of Higher School of Economics, 15(2), 279-290.

[60] Ali, B. J., \& Anwar, G. (2021). Vocabulary Learning Strategies and Foreign Language Acquisition at Private Schools. Ali, BJ, \& Anwar, G.(2021). Vocabulary Learning Strategies and Foreign Language Acquisition at Private Schools. International Journal of English Literature and Social Sciences, 6(3), 163-173.

[61] Mukherjee, M., Law, P., \& Baid, K. (2021). Emotional Intelligence, Social Intelligence, and Creativity in Early Adolescents in an Urban School Sample in Kolkata. Indian Journal of Health and Wellbeing, 12(3), 367-375.

[62] Anwar, K., \& Climis, R. (2017). Analyzing the relationship between types of advertisement and customer choice: a study of retailer stores in erbil. The International Journal of Accounting and Business Society, 25(2), 43-52.

[63] Nadaf, M., Rahimi, F., \& Gholami, Z. (2019). Designing and explaining a two-level model of emotional intelligence effect on trust and its impact on collaboration culture and individual creativity (The Case: Trainers and students of Technical and Vocational Training Organization (TVTO) in Khuzestan Province). Journal of Educational Scinces, 26(1), 119-136.

[64] Anwar, K., \& Louis, R. (2017). Factors Affecting Students' Anxiety in Language Learning: A Study of Private Universities in Erbil, Kurdistan. International Journal of Social Sciences \& Educational Studies, 4(3), 160.

[65] Ali, B. J., \& Anwar, G. (2021). Project Management and Dynamic Work Environments: The relationship between Leadership in Dynamic Work Environments in Kurdistan. Ali, BJ, \& Anwar, G.(2021). Project Management and Dynamic Work Environments: The relationship between Leadership in Dynamic Work Environments in Kurdistan. International Journal of Civil, Mechanical and Energy Science, 7(3), 10-18.

[66] Neubauer, A. C., Pribil, A., Wallner, A., \& Hofer, G. (2018). The self-other knowledge asymmetry in cognitive intelligence, emotional intelligence, and creativity. Heliyon, 4(12), e01061.

[67] Nori, R., Signore, S., \& Bonifacci, P. (2018). Creativity style and achievements: An investigation on the role of emotional competence, individual differences, and psychometric intelligence. Frontiers in Psychology, 9, 1826.

[68] Anwar, G., \& Shukur, I. (2015). Students' Attitudes towards Learning English Language in Erbil. International Journal of Social Sciences \& Educational Studies, 1(4), 17.

[69] Abdullah, N. N., \& Anwar, G. (2021). An Empirical Analysis of Natural Gas as an Alternative Fuel for Internal 
Transportation. International Journal of English Literature and Social Sciences, 6(1).

[70] Ali, B. J., \& Anwar, G. (2021). Implementation of ELearning System Readiness: The Effect of the Cost Readiness on Implementing E-Learning. Ali, BJ, \& Anwar, G.(2021). Implementation of e-learning system readiness: The effect of the cost readiness on implementing e-learning. International Journal of Electrical, Electronics and Computers, 6(3), 27-37.

[71] Paek, B., Martyn, J., Oja, B. D., Kim, M., \& Larkins, R. J. (2020). Searching for sport employee creativity: a mixedmethods exploration. European Sport Management Quarterly, 1-23.

[72] Ali, B. J., \& Anwar, G. (2021). Anxiety and Foreign Language Learning: Analysis of Students' Anxiety Towards Foreign Language Learning. Ali, BJ, \& Anwar, G.(2021). Anxiety and Foreign Language Learning: Analysis of students' anxiety towards Foreign language learning. International Journal of English Literature and Social Sciences, 6(3), 234-244.

[73] Prayetno, B. E. (2020, March). The Effect of Family Environment, Emotional Intelligence, and Creativity on Student Entrepreneurial Interest in the Faculty of Economics, Universitas Negeri Anwar, G., \& Abdullah, N. N. (2021). Inspiring future entrepreneurs: The effect of experiential learning on the entrepreneurial intention at higher education. International Journal of English Literature and Social Sciences, 6.

[74] Ali, B. J., \& Anwar, G. (2021). Porter's Generic Competitive Strategies and its influence on the Competitive Advantage. Ali, BJ, \& Anwar, G.(2021). Porter's Generic Competitive Strategies and its influence on the Competitive Advantage. International Journal of Advanced Engineering, Management and Science, 7(6), 42-51.

[75] Padang. In 4th Padang International Conference on Education, Economics, Business and Accounting (PICEEBA-2 2019) (pp. 590-598). Atlantis Press.

[76] Ali, B. J., \& Anwar, G. (2021). Business strategy: The influence of Strategic Competitiveness on competitive advantage. International Journal of Electrical, Electronics and Computers, 6(2).

[77] Ruiz-Ariza, A., Suárez-Manzano, S., López-Serrano, S., \& Martínez-López, E. J. (2019). The effect of cooperative high-intensity interval training on creativity and emotional intelligence in secondary school: A randomised controlled trial. European Physical Education Review, 25(2), 355-373.

[78] Anwar, G. (2015, April). Vocabulary Learning Strategies Of English Language Learners In Northern Cyprus. In BOOK of PROCEEDINGS (p. 226).

[79] Anwar, G., \& Shukur, I. (2015). Job satisfaction and employee turnover intention: A case study of private hospital in Erbil. International Journal of Social Sciences \& Educational Studies, 2(1), 73.

[80] Salavera, C., Usán, P., Chaverri, I., Gracia, N., Aure, P., \& Delpueyo, M. (2017). Emotional intelligence and creativity in first-and second-year primary school children. ProcediaSocial and Behavioral Sciences, 237, 1179-1183.
[81] Ali, B. J., \& Anwar, G. (2021). A study of knowledge management alignment with production management: A study of carpet manufacture in Kurdistan region of Iraq. Ali, BJ, \& Anwar, G.(2021). A Study of Knowledge Management Alignment with Production Management: a Study of Carpet Manufacture in Kurdistan Region of Iraq. International Journal of English Literature and Social Sciences, 6(2), 346-360.

[82] Anwar, G., \& Surarchith, N. K. (2015). Factors Affecting Shoppers' Behavior in Erbil, Kurdistan-Iraq. International Journal of Social Sciences \& Educational Studies, 1(4), 10.

[83] Anwar, K. (2017). The Role of Effective Leadership in Crisis Management: Study of Private Companies in Kurdistan. Qalaai Zanist Scientific Journal, 2(4), 326-338.

[84] Silva, D., \& Coelho, A. (2019). The impact of emotional intelligence on creativity, the mediating role of worker attitudes and the moderating effects of individual success. Journal of Management \& Organization, 25(2), 284-302.

[85] Ali, B. J., \& Anwar, G. (2021). Organization citizenship behaviour as a determining Factor in Business outcome. Ali, BJ, \& Anwar, G.(2021). Organization citizenship behaviour as a determining Factor in Business outcome. International journal of Rural Development, Environment and Health Research, 5(2), 17-25.

[86] Toyama, H., \& Mauno, S. (2017). Associations of trait emotional intelligence with social support, work engagement, and creativity in Japanese eldercare nurses. Japanese Psychological Research, 59(1), 14-25.

[87] Anwar, G., \& Shukur, I. (2015). the impact of recruitment and selection on job satisfaction: Evidence from private school in Erbil. International Journal of Social Sciences \& Educational Studies, 1(3), 4-13.

[88] Anwar, G., \& Shukur, I. (2015). Students' Attitudes towards Learning English Language in Erbil. International Journal of Social Sciences \& Educational Studies, 1(4), 17.

[89] Ali, B. J., \& Anwar, G. (2021). Intellectual capital: A modern model to measure the value creation in a business. Ali, BJ, \& Anwar, G.(2021). Intellectual capital: A modern model to measure the value creation in a business. International journal of Engineering, Business and Management, 5(2), 31-43.

[90] Anwar, K. (2016). Comparison between cost leadership and differentiation strategy in agricultural businesses. Custos $\mathrm{E}$ Agronegocio on Line, 12(2), 212-231.

[91] Yildırım, F., Trout, I. Y., \& Hartzell, S. (2019). How are entrepreneurial intentions affected by emotional intelligence and creativity?. Periodica Polytechnica Social and Management Sciences, 27(1), 59-65. 